\title{
An Innovative and Customized Cheek Plumper Attachment to Enhance Esthetics in the Complete Denture Patients
}

\author{
Vaishnavi Inginshetty ${ }^{1}$, Swapnali B Ghumare ${ }^{2}$, Neeta Rana ${ }^{3}$
}

\begin{abstract}
This case report aims to enhance the esthetics in the complete denture patients with the customized attachment cheek plumper by an innovative method. The loss of teeth in patients leading to a handicap can be severe due to the impairment of masticatory function and facial disfigurement leading to a negative psychological impact on the individual. To improvise on this, apart from the regular measures of teeth arrangements to obtain lip support, excellent denture esthetics can be obtained by providing additional support to the slumped tissues. A 62-year-old male patient with a sunken cheek appearance walks into the department a complete denture fabrication with cheek plumper is pronounced. This article narrates a basic, effortless, non-invasive, and innovative treatment substitute to enhance facial appearance in a completely edentulous patient with sunken cheeks by implementing detachable cheek plumper/cheek lifting prosthesis using customized attachments. The advantages of these attachments are that it allows ease of placement and cleaning; easily available and economic; due to their limited size can be easily jabbed in the denture flange. The present technique of cheek plumper/cheek lifting customized attachment can also be easily used in unconventional cases like restricted mouth opening, facial palsy, and so on.

Keywords: Cheek, Cheek plumper prosthesis, Denture esthetics, Detachable, Device, Esthetics, Plumper, Prosthetic, Removable partial denture, Sunken.

International Journal of Prosthodontics and Restorative Dentistry (2021): 10.5005/jp-journals-10019-1312
\end{abstract}

\section{BACKGROUND}

In today's world, the self-presentation of beauty and perceptions of others plays an important role in developing the identities of a person at any stage of life. The sunk-in cheek appearance due to their extreme visibility is a predominant factor in determining facial esthetics. The form of cheeks is determined by the support provided by internal structures-teeth, ridges, or dentures. ${ }^{1}$ The main underlying etiology would be extraction of molars, tissue thinning due to aging, or weight loss can cause concavities below the malar bone leading to hollow cheeks or sunken cheeks. ${ }^{2}$

The complete denture should not only replace missing teeth but the prosthesis must also restore the facial contours. It can be fulfilled by proper denture extensions and contours of denture flange. However, sometimes even with proper extensions of the denture flange and countering the issue is not solved in some cases like patients with hollow or sunken cheeks, extra support has to be provided. This can be done using cheek plumper or cheek lifting appliances. Cheek plumpers or cheek lifting appliances have been used previously to improve esthetics and psychological profile in patients. $^{3}$

The purpose of this case report is to enhance the esthetics in the complete denture patients with the customized attachment cheek plumper by an innovative method.

\section{Case Description}

A male patient of age 62 years visited our institute for replacement of his missing teeth. On clinical examination, it was found that the maxillary arch ridge was favorable for conventional complete denture and mandibular arch ridge with mild posterior ridge resorption. The patient was conscious, coherent to the surroundings, and without any relevant medical history. On

\begin{abstract}
${ }^{1-3}$ Department of Prosthodontics and Crown and Bridge, Maratha Mandal's Dental College and Research Center, Belagavi, Karnataka, India

Corresponding Author: Vaishnavi Inginshetty, Department of Prosthodontics and Crown and Bridge, Maratha Mandal's Dental College and Research Center, Belagavi, Karnataka, India, Phone: +91 9886264120, e-mail: vaishnavi.inginshetty@gmail.com

How to cite this article: Inginshetty V, Ghumare SB, Rana N. An Innovative and Customized Cheek Plumper Attachment to Enhance Esthetics in the Complete Denture Patients. Int J Prosthodont Restor Dent 2021;11(2):97-99.

Source of support: Nil

Conflict of interest: None
\end{abstract}

extraoral examination, the major finding was sunken cheeks. The patient was certain of them and preferred a prosthesis that would make his face look adequately intact. The patient was educated and advised for an upper and lower complete denture with removable cheek lifters for the maxillary denture.

On the first appointment, primary impressions were made with impression compound. Primary casts were retrieved on which the spacer with full spacer designs was adapted and special trays were fabricated. During the next appointment, border molding was performed and secondary impressions were taken using light body impression material. Maxillo-mandibular relations were scheduled for the next appointment. While adjusting the upper rim, wax blocks were made accordingly for the required length, breadth, and checked for patient's visibility at rest and during speech. To correct the sunken cheek appearance at the buccal surface of the maxillary dentures and fullness of the face was checked. Using putty indexes detachable wax blocks were 
fabricated. Try-in was done along with the detachable wax blocks to reconfirm the esthetics (Fig. 1).

Acrylization of the cheek plumpers was done separately using heat cure acrylic resin. After curing the cheek plumpers were retrieved, trimmed, and polished. The cheek plumpers were attached to the conventional denture using an innovative technique. This innovative technique makes use of rubber housings which are used to cover the implant analog during pouring an impression and an implant mount (an implant insertion tool) of the Osstem implant system was used (Fig. 2), which are usually discarded after retrieving the implant from it.

At the desired location in the maxillary buccal flange of the conventional denture and the cheek plumper, space is made by trimming to incorporate the rubber housing and the implant mount, respectively. These both were secured in place using autopolymerizing acrylic resin (Fig. 3).

Denture insertion was done and adequate clearance of the cheek plumper from the occlusal table was verified (Fig. 4). After insertion, the patient was satisfied by the improved esthetics and fit of the prosthesis (Figs 5 and 6). The patient was educated regarding the attachment, detachment of the cheek plumper and was asked to report for the regular follow-up evaluation.

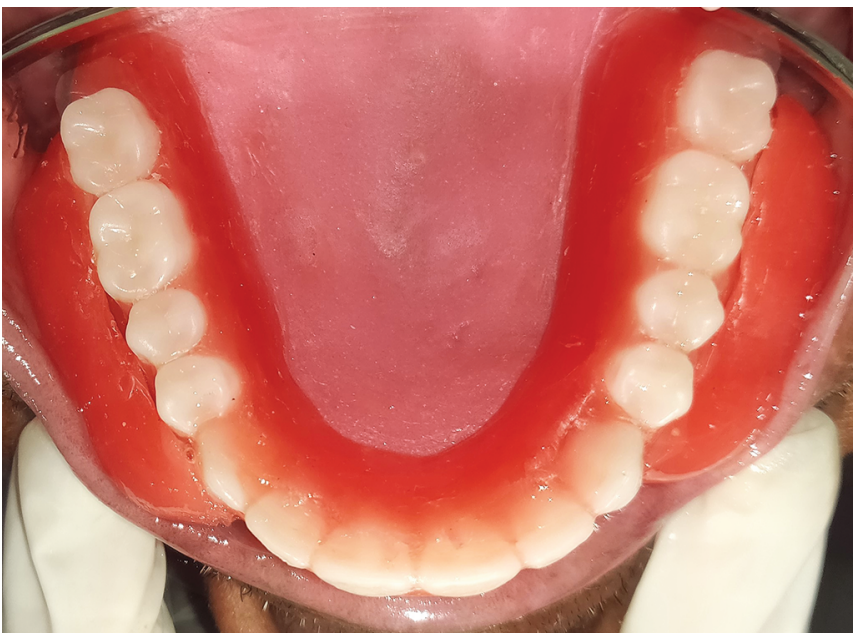

Fig. 1: Wax try-in, occlusal view

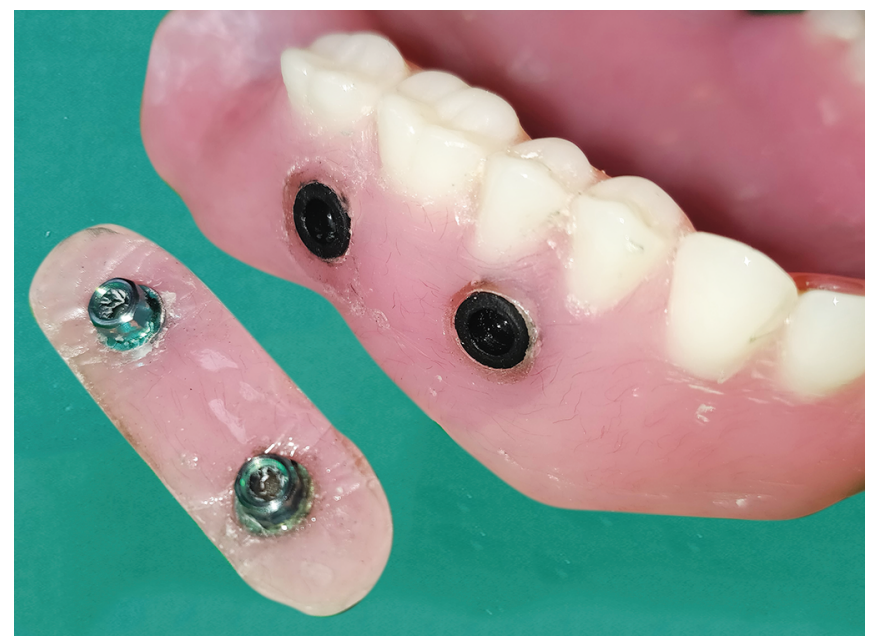

Fig. 3: Attachments in final prosthesis

\section{Discussion}

These detachable plumper aids in reducing the weight of the final prosthesis and provide easy placement of the prosthesis. They let the patient disconnect the plumper and use the denture alone if required. They can be easily inserted in patients with reduced mouth opening.

In the present case, a detachable cheek plumper prosthesis using rubber housing and the implant fixture mount (an implant insertion tool) of the Osstem implant system was used. These components were planed because they are easily available, costeffective, reliable, and also helped in the easy fabrication of the prosthesis.

Different types of attachments for its use with cheek plumpers have been discussed in the literature such as magnet, ${ }^{4}$ push button, ${ }^{5}$ Dowel pin, ${ }^{6,7}$ and springs. ${ }^{8}$ However these attachments have certain disadvantages like short-term durability, corrosiveness, and high cost. Magnet and push button may cause rotation of the cheek plumpers during oral function. Also, magnets can cause interferences in patients with cardiac pacemakers and implantable cardioverter-defibrillators. ${ }^{6}$ The results of closed magnetic field ${ }^{4}$ on the health of oral tissues require to be assessed. ${ }^{4}$

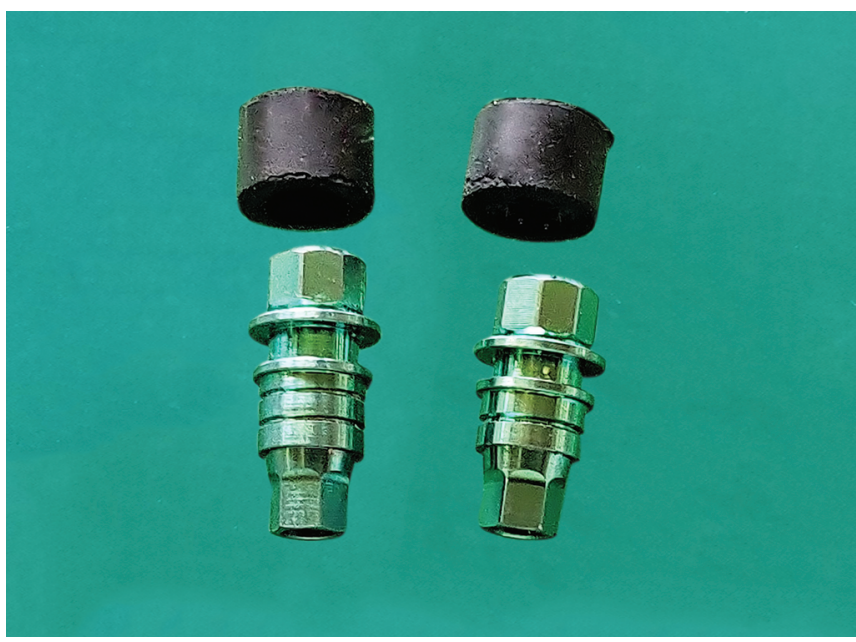

Fig. 2: Attachment components

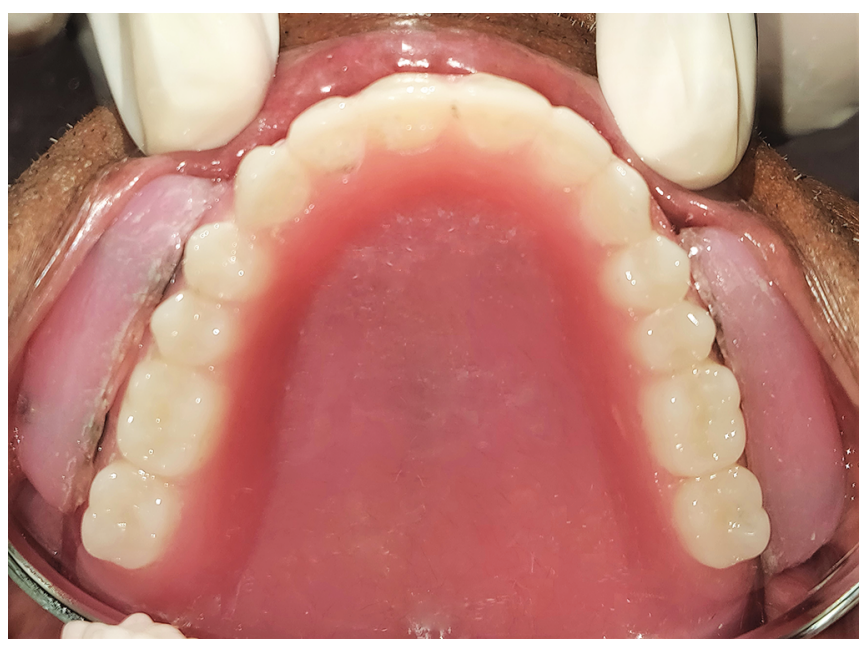

Fig. 4: Final prosthesis occlusal view 


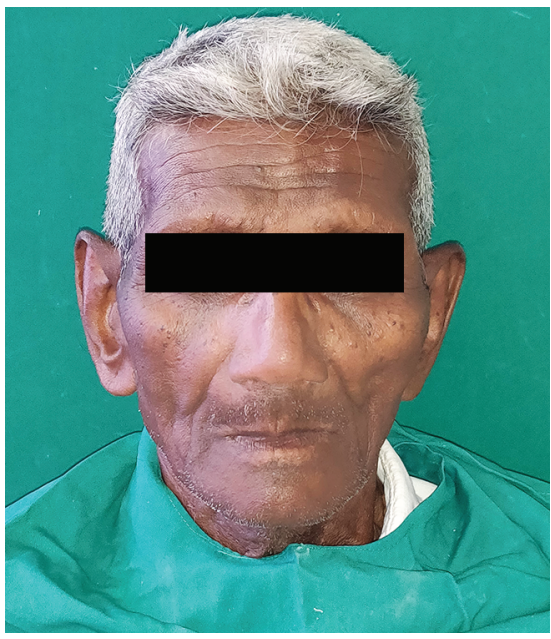

Fig. 5: Preoperative photograph

Rectifications of drooping of cheeks can be done by different methods like reconstructive plastic surgery, ${ }^{9}$ injecting the botulinum toxin (BOTOX) in the facial muscles, and different types of prosthesis. ${ }^{9}$ Conventional cheek plumper which is a single unit appliance with extensions on either side of the posterior flange of a denture base leads to muscle fatigue and decreased retention. ${ }^{10}$ Therefore, detachable cheek plumper provides an advantage to detach the cheek plumper if they lead to muscle fatigue on longterm use.

\section{ConcLusion}

The complete dentures with added cheek plumper, apart from restoring the masticatory function also aid in improving overall facial esthetics which provides a positive psychological impact on the patients. It has the combined advantage of easy insertion and removal whenever required. This avoids destabilization of the denture, especially during mastication. The incorporation of rubber housing and implant mount which are easily available and economic also provided a simple method of fabrication.

\section{References}

1. Keni NN, Aras MA, Chitre V. Customised attachments retained cheek plumper prosthesis: a case report. J Indian Prosthodont Soc 2012;12(3):198-200. DOI: 10.1007/s13191-012-0132-y.

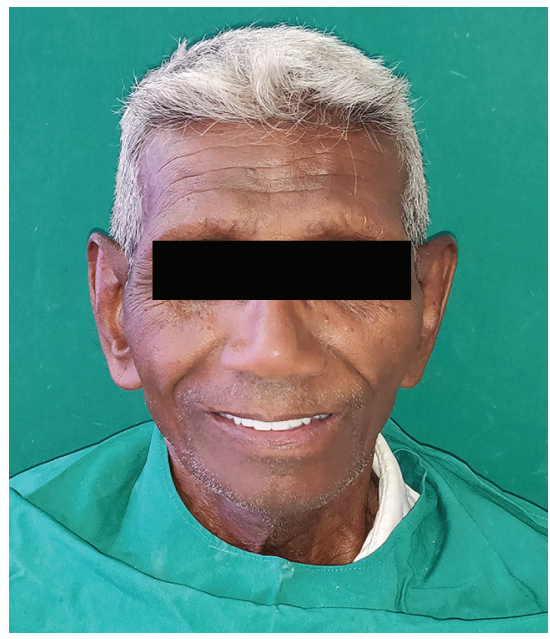

Fig. 6: Postoperative photograph

2. Bains JW, Elia JP. The role of facial skeletal augmentation and dental restoration in facial rejuvenation. Aesthet Plast Surg 1994;18(3): 243-246. DOI: 10.1007/BF00449788.

3. Hitoshi M, Chiaki K, Takashi O, et al. Lip plumper prosthesis for a patient with a marginal mandibulectomy: a clinical report. J Prosthet Dent 2004;92(1):23-26. DOI: 10.1016/j.prosdent.2004.04.019.

4. Pooja G. Magnet retained cheek plumper in complete denture. J Oral Dent Health Res 2020;2(1):110.

5. Raghavendraswamy KN, Chauhan S, Dhakshaini MR, et al. Novel die pin cheek plumper attachment-an innovative to enhance facial esthetics in completely edentulous patients. Int J Curr Res 2018;10:50668-50671.

6. Gade JR, Kumbhalwar AS, Johari SV. Management of sunken cheeks and esthetic rehabilitation of a patient by using detachable cheek plumpers in a conventional complete denture with a new attachment system: a case report. Eur J Mole Clin Med 2021;7(11):8189-8196.

7. Pudi S, Kota S, Ch KKVG, et al. An innovative technique using a stainless steel double die pin retained cheek plumper in complete denture esthetics: a case report. Cureus 2019;11(11):e6197. DOI: 10.7759/cureus.6197.

8. Kumar B, Sandhu PK, Bhatia S, et al. An innovative solution to slumped cheeks:"Spring Retained Cheek Plumper"-a case report. J Dent Med Sci 2017;16(01):55-57. DOI: 10.9790/0853-1601035557.

9. Kumar P, Khattar A, Goel R, et al. Role of botox in efficient muscle relaxation and treatment outcome: an overview. Ann Med Health Sci Res 2013;3(1):131. DOI: 10.4103/2141-9248.109489.

10. Saoji S, Agrawal S, Bhoyar A, et al. Restoring esthetics with magnet retained cheek plumpers. Ind J Comprehen Dent Care 2015;5: $651-654$. 